\title{
GIS/Remote sensing techniques for resource management and biodiversity protection in mountainous regions
}

\author{
John All \\ Department of Geography and Geology, Western Kentucky University, USA; e-mail: John.all@wku.edu
}

\begin{abstract}
Biodiversity protection in mountainous regions requires effective fact-driven resource management techniques. Geoinformatic tools including GIS and remote sensing can be integrated to provide regional-scale data products across time for use in strategic and management level policymaking. Several principles are discussed to ensure that geoinformatics data and analysis can effectively contribute to resource management by clarifying issues and minimizing misinterpretation. A case study in the Chilean Andes elucidates these principles. Biological impacts of recent climate changes have not been equal across different ecosystems and stable forest ecosystems provide the best response to climate change. Geoinformatics is used to differentiate functional ecological groups and evaluate long-term resilience to climate change.
\end{abstract}

Key-words: Chilean Andes, climate change, mountain ecosystems, geoinformatics, vegetation.

\section{Introduction}

Policy questions regarding environmental issues must rely on science to provide accurate facts for decision-making. Geoinformatic tools including GIS and remote sensing can be integrated to provide regional-scale data products across time for use in strategic and management level policymaking (Molenaar 2005). Geoinformatics refers to the array of new digital analysis tools such as Geographic Information Systems (GIS), remote sensing, and geostatistics. Geoinformatics is valuable because it allows for regional-scale assessments and assessment of information across time to examine the assumptions that underlie policy and management. Metadata is often touted as the way in which to avoid many inherent problems with geoinformatics. However, metadata can easily be lost, incomplete, or misunderstood, so it is not the final solution.

This manuscript will discuss some general geoinformatics principles and traps to avoid. It will then examine techniques for using geodata in the Chilean Andes. Different ecological groups are examined and compared to one another and correlated to climate variability. This demonstration of techniques for mountainous areas is replicable for any such region on Earth and should provide guidance for developing other analyzes for resource management needs. Geoinformatics is extremely valuable because it allows the integration of huge amounts of data into a single database, which can then be probed for patterns such as on past extreme climatic events and extinctions (Lane et al. 2005).

There is a danger of misuse or misunderstanding that pervades all digital datasets and its use may not be appropriate if experience with this technology is extremely limited (Musinguzi et al. 2004). In China, digital datasets are helping to correct abuses of political authority as well as mistakes in understanding the outcomes of resource management decision-making (Qiao and Xiaofei 2004). Romania is targeting much of their water pollution management goals to include geoinformatics databases (Zaharia 2005). Targeted resource allocation can be greatly improved using geoinformatics and many management systems are achieving greater efficiency through this technology in Africa and the Middle East (Petja et al. 2004; Rida et al. 2004).

\section{General Geoinformatics and Resource Management Principles}

- It is very important to include the entire ecosystem or watershed or other physical delineation that creates a logical boundary rather than typical arbitrary political boundaries. This is often difficult because data collection is conducted by government agencies using politicallybased sampling frameworks (e.g. national, regional, or local boundaries). In spite of this organizational dysfunction, environmental event occurrence in a political entity often has ecological ramifications for adjacent localities within a given physical region.

- In order to be valid for management or policy use, only 'complete' data should be used. Complete data should be defined as where $80 \%$ or more of event occurrence is measured. This will exclude anecdotal data such as fauna habitat maps based upon encounters; only systematic data collection with a very high degree of measurement 
success should be utilized in the policy arena. While this limitation excludes the use of geoinformatics from management venues where it is currently incorrectly employed, such an approach is superior to misleading dataset generation, analysis, and presentation.

- Single season or single year datasets are rarely valid. Interannual variations in climate, predation, competition, etc limit the usefulness of such 'snapshot' data. Multitemporal data is crucial to show the past, document changes and plan the future.

- Generalized categorization is never appropriate for policy applications. Land cover classifications such as urban or mixed forest are far too subjective and misleading. Such terms can be abused by proponents of a specific viewpoint in a policy debate. Instead, all parameters throughout the process should be specifically defined so that anyone could re-analyze the data without further input from the author - e.g. don't indicate urban, instead use a 17-22\% impervious surface category.

- Gathering data must be a cost-effectively repeatable activity so that changes can be evaluated, for long term monitoring, and so that outside groups can evaluate and trust results. Also, when data is made freely available, it allows various groups to perform additional analysis and potentially discover new patterns. Agencies such as the US National Science Foundation (NSF) espouse this type of approach (Lane et al. 2005). Also, this process is being used internationally for developing world environmental datasets (Molenaar 2005; Barry and Khan 2005). Remote sensing imagery is extremely valuable in this regard because there are many data sets such as Landsat MSS, TM, ETM, AVHRR, and MODIS that are available on-line without cost.

\section{TWO MAJOR GEOINFORMATICS TRAPS TO AVOID}

Scope issue: Limit the analysis when the data is incomplete data is usually limited temporally or spatially and a common mistake is to analyze limited datasets and then extrapolate the results to the whole. While this is appropriate, perhaps, for theoretical study, the non-linearity of environmental systems and fluxes means that such an approach is inherently limited in absolute accuracy and is thus not appropriate for policy needs.

Completeness issue: Only complete datasets should ever be used. Data based on personal observation is rarely complete. Using data based on single person's observations or other anecdotal data is the antithesis of science, yet is very easy to do with geoinformatic tools. This snapshot data would include a satellite image during drought or flood, species ranges from a single collection trip, or other non-systematic data collection.

In summary, in order to combat the snapshot geoinformatics analysis, time-series data should be used whenever practicable. If this type of information (such as remotely sensed data or other automated collection system data) is unavailable, then such a major limitation on the analysis should be explicitly noted and/or the analysis not undertaken. Overall, if there is a problem with the data or applicability, then the best options always is to refuse to perform the analysis based upon the flaws. The danger of misinterpretation and misuse is great enough to warrant this limitation (Musinguzi et al.2004).

\section{Case Study: Chilean Andes Mountains}

In order to demonstrate some of these principles, a case study of vegetation response to climate variability in Chile will be discussed. The magnitude of interannual climate variability can be examined by comparing vegetation vigor in agriculture and natural vegetation in Chile. Vegetation response to climatic conditions under different management regimes within the same region is compared using single-image ratioing techniques (All and Yool 2004). By comparing highly managed agricultural production with unmanaged natural vegetation vigor for several different ecosystems, an overall assessment of climate change impacts can be ascertained. The Intergovernmental Panel on Climate Change (IPCC 2009) is the primary authority on global change. Its most recent report emphasizes that adaptability of rural societies to climatic change will be determined by the health of the ecosystem, which in turn is closely related to the policies and cultural practices governing resource use.

The region south of Santiago is the study area (Fig. 1). The moisture gradient grows wetter as one moves south through Chile from the Atacama Desert and Santiago is the transition zone where rain-fed agriculture begins. The climate is Mediterranean and climate processes are relatively simple to understand (Mooney 1977). This study divides the landscape into five categories for analysis of vegetative vigor - natural grasslands, irrigated farming, dryland farming, natural coastal forests, and Andean mountain forests. Comparing the relative impact of climate change signals for these different management regimes will offer insight into potential coping mechanisms for climate variability and change.

Vegetation in north-central Chile is precariously dependant upon rainfall variations such that annual fluctuations can have large impacts and anomalous climate behavior should be easily identified through satellite images (Meserve et al. 1995; Dillon and Rundel 1990). The land is split between small-scale communal property and better capitalized private lands and this will provide an excellent opportunity to contrast agricultural realities. 


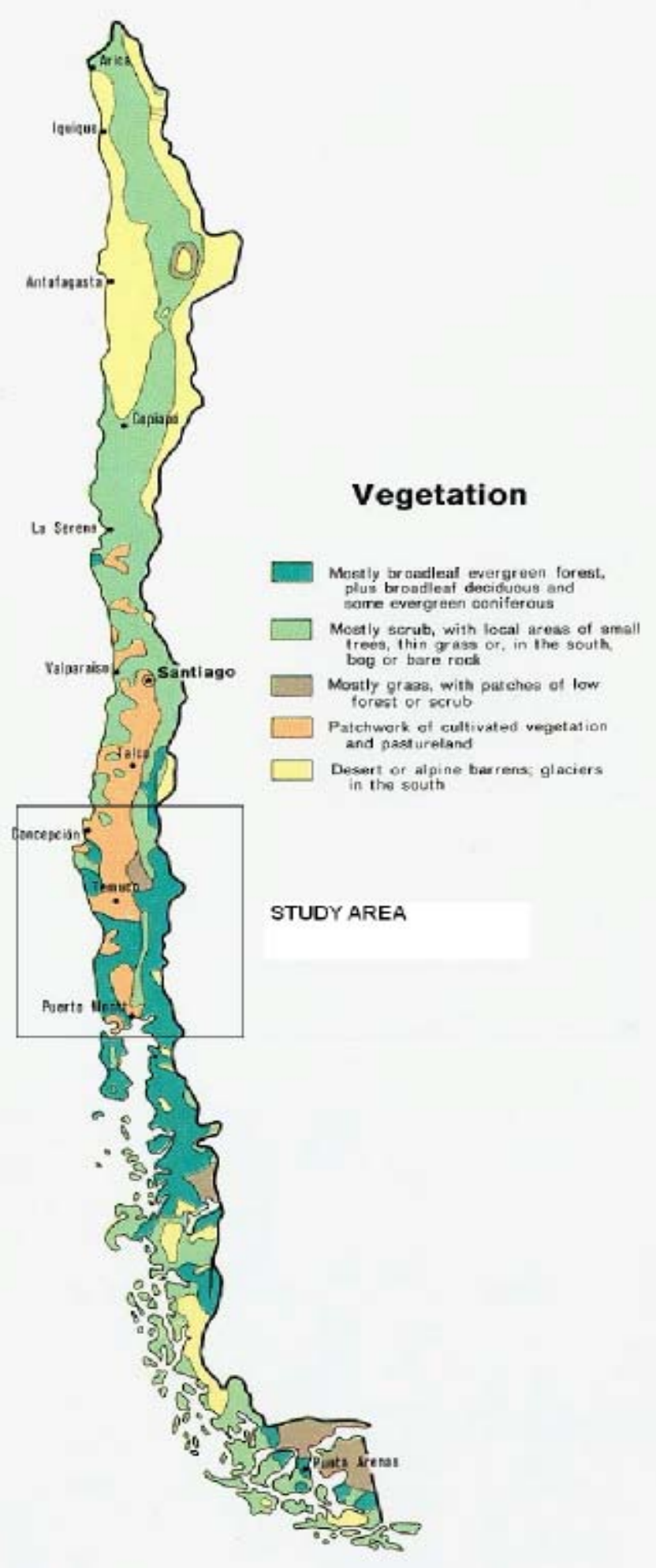

Fig. 1. Study area in central Chile.

\section{Methods}

Remote sensing technology in combination with geographic information systems (GIS) can provide very reliable information on vegetation cover. The data chosen for this study was NASAMODIS system $1 \mathrm{~km} \times 1 \mathrm{~km}$ pixel satellite images. While Landsat TM or ETM would provide smaller pixel size $(30 \times 30 \mathrm{~m})$, MODIS images are available everyday of the year and Landsat TM are only available twice a month. If clouds are present, this temporal factor can greatly limit data availability. MODIS products are computed from atmospherically corrected bi-directional surface reflectance that have been masked for water, clouds, heavy aerosols, and cloud shadows. For example, the blue band helps remove residual atmospheric contamination caused by smoke and sub-pixel thin clouds.

The MODIS data was processed using maximum value compositing (Lambin and Ehrlich 1997) into a bi-weekly maximum and entered into a Geographic Information System (GIS) to perform principal components analysis and determine a seasonal development curve to reveal which areas have had the greatest perturbation. Examining natural, small-scale, and large-scale farmland all on the same image allows for the data to be ratioed thus removing the impact of sensor differences across years (All and Yool 2004). The information was pre-processed and spatially co-registered using GPS coordinates (All 2006). Supervised classifications and change detection was performed to determine actual vegetation classes through groundtruthing.

By subtracting red from near-infrared spectral channels (Fig. 2) and dividing by the sum of the two, a Normalized Difference Vegetation Index (NDVI) can be derived to effectively measure photosynthetic activity (Fig. 3, Marsh et al. 1992). NDVI values vary with absorption of red light by plant chlorophyll and the reflection of infrared radiation by water-filled leaf cells (NOAA 2003). NDVI will provide an estimate of vegetation health over the study time period and a means of monitoring the spatial extent of farm and natural vegetation (Fig. 4). NDVI is calculated from the reflected solar radiation in the near-infrared (NIR) and red (RED) wavelength bands via the algorithm: NDVI = (NIR - RED)/(NIR + RED $)($ NOAA 2003). This calculation determines Intercepted Photo-synthetically Active Radiation (IPAR), which is normally correlated with photosynthesis. Photosynthesis occurs in the healthy green parts of plant material and so the NDVI can be used to estimate green vegetation.

Groundtruthing the resulting images is crucial to register such a large amount of data from different sensors. Once the signals are cleaned up then spatial areas of anomalous vegetative response can be determined. Areas of greater resilience will also be studied in order to provide a check on the research. This study will identify areas of change as either climate-driven or anthropogenic and such disturbance can be caused by climatic, social or political stimuli and differentiating these will be the key to the vegetation impacts work in this study. 


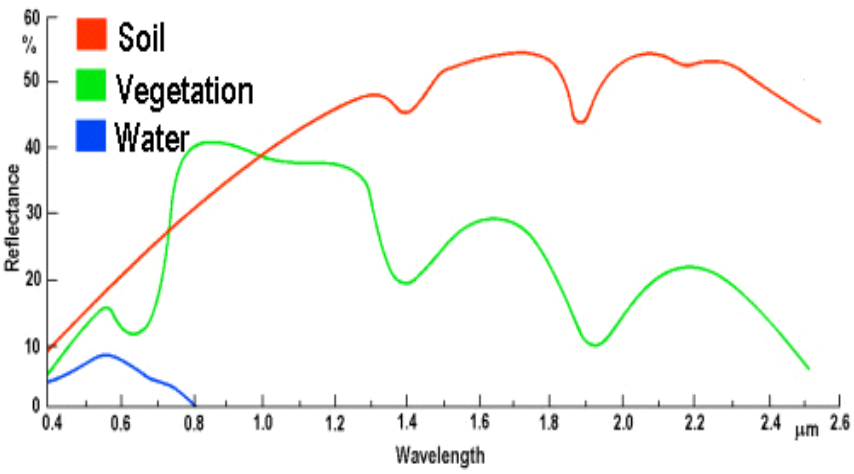

Fig. 2. Electromagetic spectrum reflectance curves.

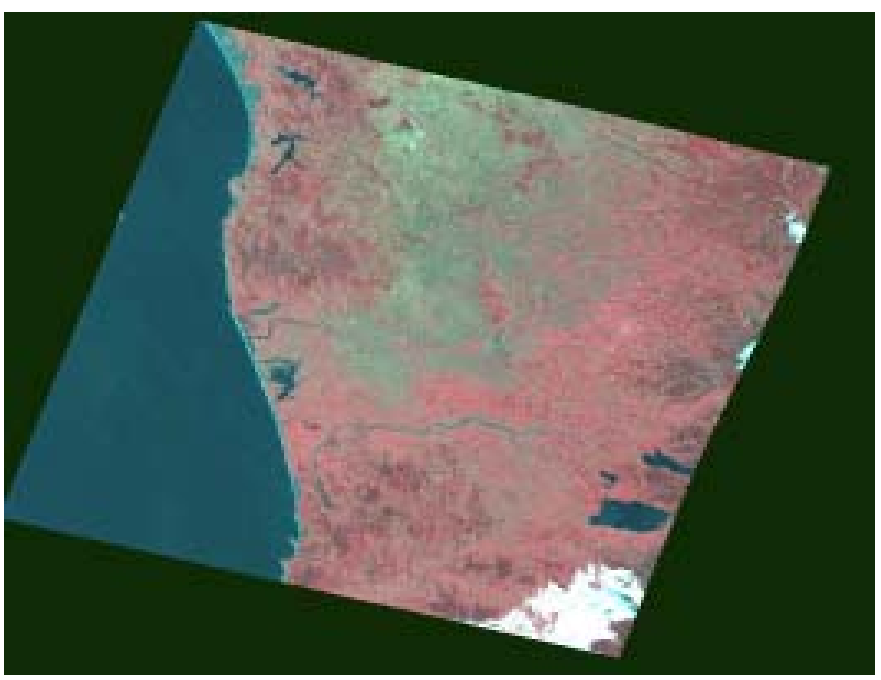

Fig. 3. NASA Landsat Image of the study area in Chile. The dark blue areas are ocean and land. The white is mountain glaciers.

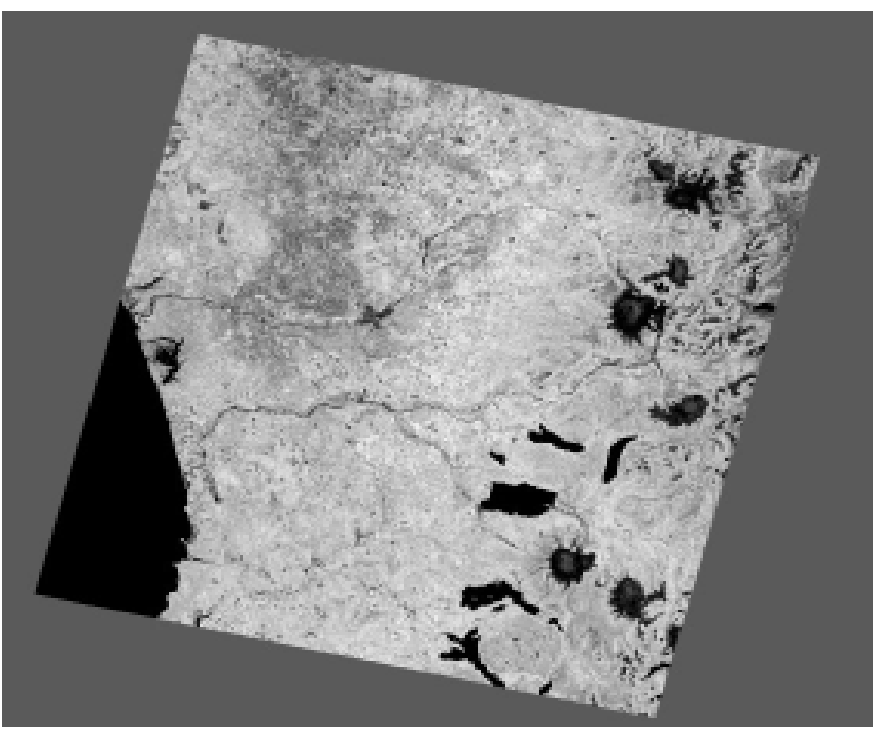

Fig. 4. NASA Landsat NDVI image created from one similar to Fig. 3. Areas in black are water/ice. White is vegetation.

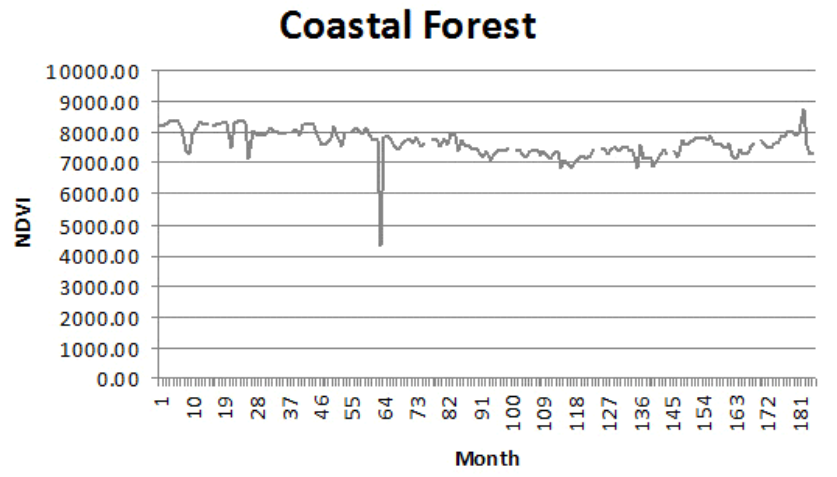

Fig. 5. Coastal forests in Chile are evergreen needle species such that there is little variability summer to winter.

\section{Mountain Forest}

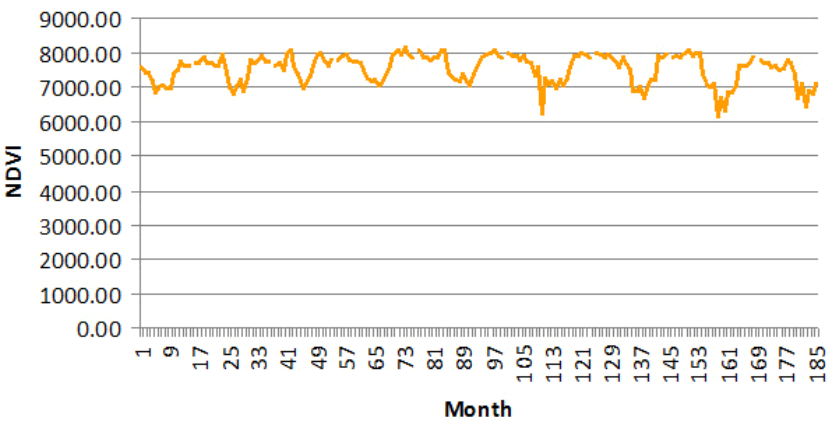

Fig. 6. Mountain forests along the Andean mountains are evergreen needle species under drier conditions. Snowfall impacts the NDVI values.

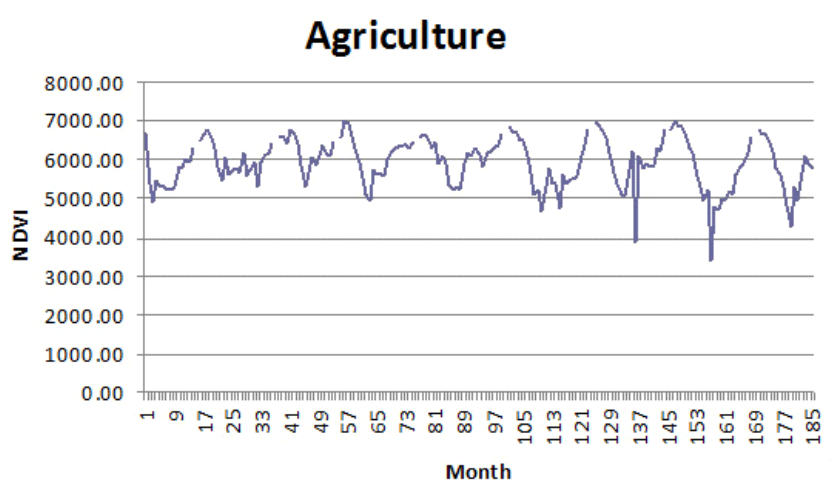

Fig. 7. Dryland agriculture in Central Chile. These lands are rainfall dependant and NDVI is highly variable depending on precipitation.

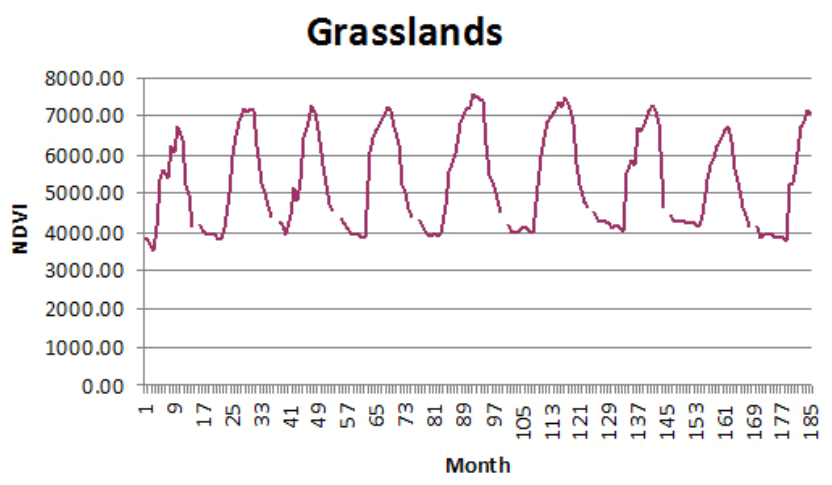

Fig. 8. Natural grasslands in Central Chile. These lands are not intensively grazed and are the most arid of the areas examined. 




Fig. 9. Irrigated agriculture near Santiago, Chile. This is the primary economic activity in the area. The prolonged water availability leads to a lengthened peak in the summer NDVI values and results in far more total annual productivity per hectare than any other managed land unit. These lands are irrigated from melting glaciers in the Andes and this is not a sustainable water source.

\section{Results and Discussion}

Various management areas were subset from the data and the NDVI averaged for each month. This data is plotted from Month 1 (January, 2000) to Month 181 (December, 2008) in bi-weekly increments (Figs 5-9). The land use types are as follows: coastal forest (warm wet conditions in low elevations along the coast), mountain forest (Andean forests with cool drier conditions), dryland rain-fed agriculture, rain-fed grasslands (semi-arid and unmanaged), and irrigated agriculture. The NDVI was set on a 0 to 10,000 scale to separate out small differences in vegetative response.

Once the initial NDVI values for a given ecotype have been established, inter-scene ratios of ecotypes were created to elucidate which land use types had the greatest productivity per hectare. Also, vegetation stability can be examined in order to determine which systems are most resilient in the face of climate variability. The graphs are interpreted by examining how NDVI varies such that if the ratio is 1.00 , then each ecosystem is growing equally expected in winter or during the dry months when there is no precipitation so that each ecotype is effectively at zero or no growth. If the number is above 1.00 , then the upper ecotype in the ratio is growing faster than the lower one such that 2.00 means that there is double the chlorophyll activity and 3.00 is triple the growth.

In Fig. 10, agricultural land is slightly more productive than grasslands during the growing season, but both are relatively unproductive because they are dependant upon limited rainfall. In the winter, the ratio drops below 1.00 because the agricultural lands are plowed and all plant material removed, while the grasslands retain limited biomass.

In Fig. 11, coastal forests are seen to more productive than grasslands. In both Figs 10 and 11, the high variability of the grasslands and low productivity means that they are the least resilient system and most likely to suffer during climate variability.
In Fig. 12, the inherent instability of rain-fed agriculture in semi-arid regions is clear. While during some years the rain-fed lands are very productive, the unstable vegetation index reveals the limitations to climate adaptation in the lands.

Surprisingly, the irrigated farmland in Fig. 13 is no more than fifty percent more productive than nearby grasslands. However, while the peak production is not substantially higher, the prolonged production, which results in a wider curve during the wet months, means that overall productivity of the land is much higher. In addition, irrigation tends to buffer interannual variability and provide the most climatologically robust management system.

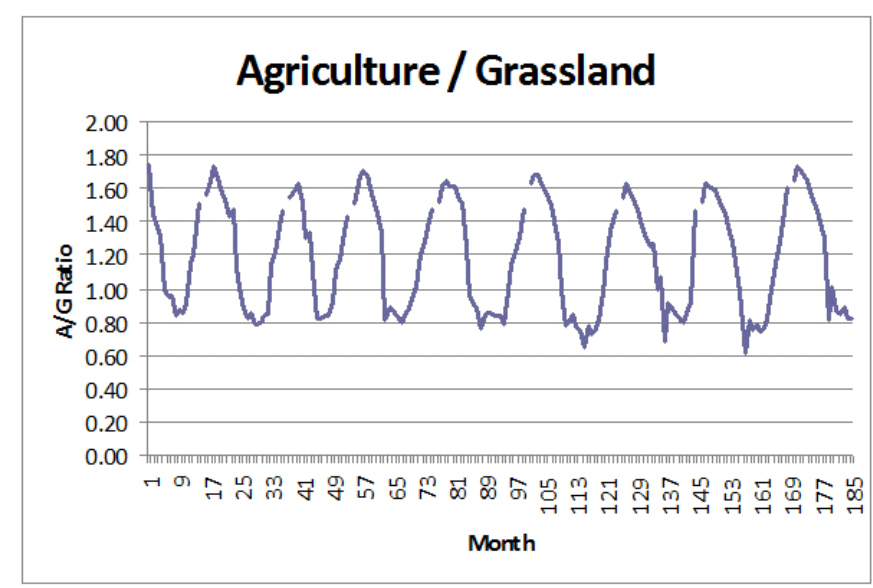

Fig. 10. Rain-fed agriculture NDVI/grasslands NDVI.

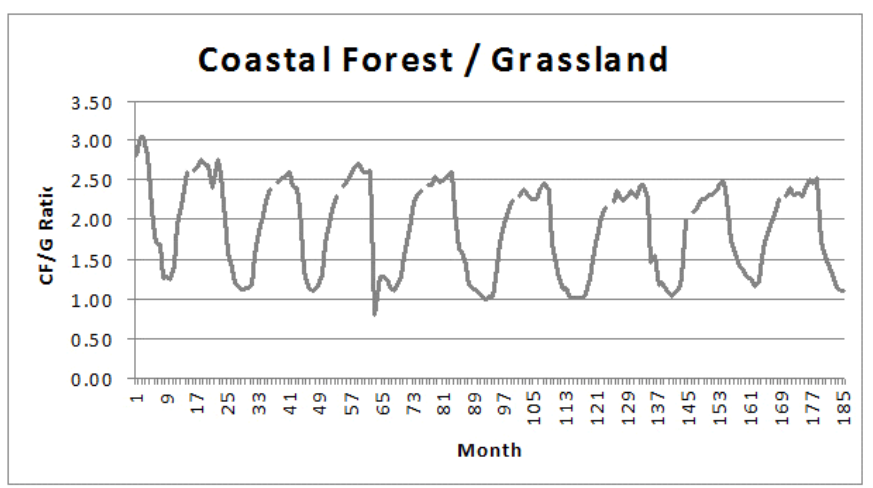

Fig. 11. Coastal forest NDVI/grassland NDVI.

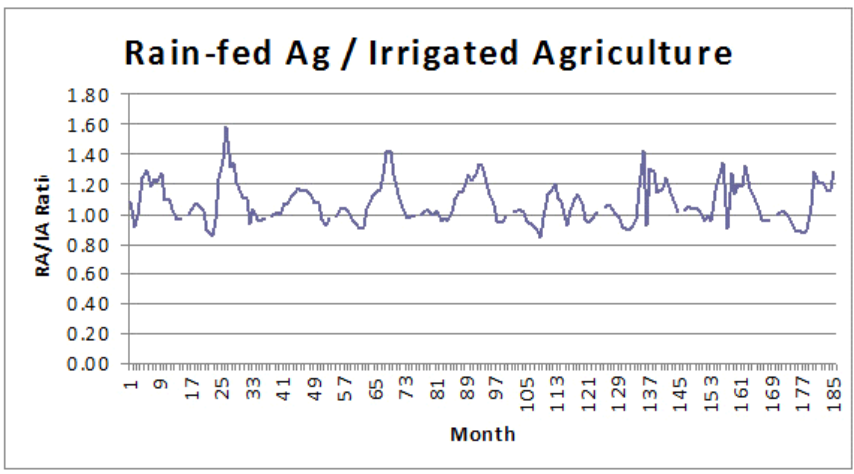

Fig. 12. Rain-fed agriculture NDVI/irrigated agriculture NDVI. 




Fig. 13. Irrigated agriculture NDVI/grassland NDVI.

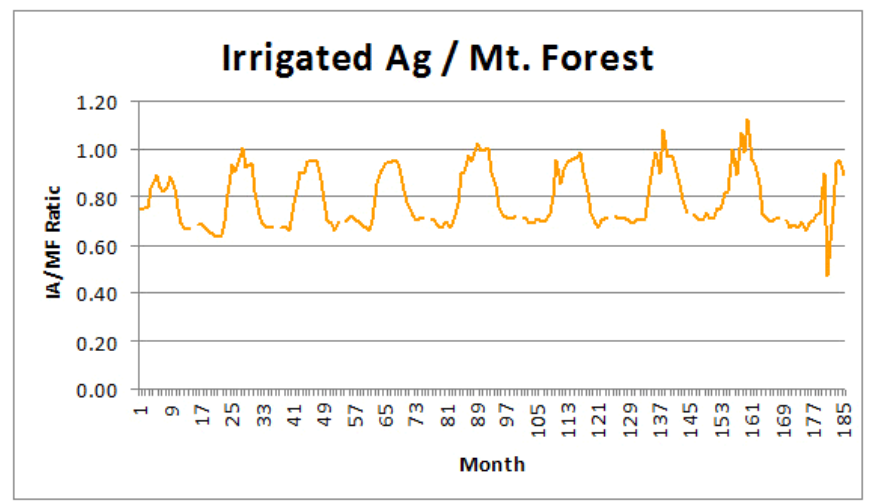

Fig. 14. Irrigated agriculture NDVI/mountain forest NDVI.

Fig. 14 is very revealing. It shows that mountain forests are more productive than even irrigated agriculture. However, high interannual variability in the forest ecosystem means that this is not invariably true. During years of unusual climate patterns, such as during the last two years in Fig. 14, mountain productivity can decline and/or be negatively affected by other processes such as insect outbreaks or fire.

\section{Conclusions}

By examining each land use type and its response to climate fluctuations, it becomes clear that systems with more water available and less anthropogenic disturbance are more robust typically. Irrigated agriculture is more resilient than rain-fed agriculture which is more resilient than rain-fed grasslands. However, the forest areas have far greater productivity per year than any managed system. By maintaining a mix of eco-types, climate resilience is maximized and a more robust set of livelihood options are available.

Geoinformatics techniques allow resource managers to quantify ecosystem responses to climate variability. Once vegetation indices are created for various ecosystems and land use types, these can be compared and the relative benefits numerically determined. This allows resource managers to make informed decisions about capital allocation based on factors such as irrigation available, forest type within their purview, etc. This analysis can take place at any scale and for any ecotype defined by the user. The importance of these geo-informatics systems will grow as populations grow and climate changes adversely affect ecosystems and global biodiversity.

\section{References}

All J. 2006. Colorado River floods, droughts, and shrimp fishing in the upper Gulf of California. Environmental Management 37: 111-125.

All J.D. and Yool S. 2004. Indexing endangered species risk in the Colorado River Delta, Mexico using AVHRR NDVI time series data. Geocarto International 19(4): 5-13.

Barry M. and Khan K. 2005. Law and policy implications of multimedia land records: The Talking Titler Project. In: From Pharaohs to Geoinformatics, FIG Working Week 2005 and International Conference on the Global Spatial Data Infrastructure (GSDI-8) (April 16-21, 2005), Cairo, Egypt.

Dillon M.O. and Rundel P.W. 1990. The botanical response of the Atacama and Peruvian desert floras to the 1982-83 El Niño Event. In: Global Ecological Consequences of the 1982-83 El Niño-Southern Oscillation (P.W. Glynn, ed.), pp. 222-234. Elsevier Science Publishers, New York, USA.

IPCC (Intergovernmental Panel on Climate Change) 2009. Climate Change 2008-Impacts, Adaptations and Mitigation of Climate Change: Scientific Technical Analysis. Press Syndicate. University of Cambridge, New York, USA.

Lambin E.F. and Ehrlich D. 1997. Land-cover changes in Sub-Saharan Africa (1982-1991): application of a change index based on remotely sensed surface temperature and vegetation indices at a continental scale. Remote Sensing and Environment 61: 181-200.

Lane R., Epp D. and Wagner T. 2005. Geoinformatics in sedimentary geology and paleontology at the US National Science Foundation. Geophysical Research Abstracts 7: 23-25.

Marsh S.E., Walsh J.L., Lee C.T., Beck L. and Hutchinson C.F. 1992. Comparison of multitemporal NOAA-AVHRR and SPOT-XS data for mapping land cover dynamics in the West African Sahel. International Journal of Remote Sensing 13: 2997-3016.

Meserve P.L., Yunger J.A., Gutierrez J.R., Contreras L.C., Milstead W.B., Lang B.K., Cramer K.L., Herrera S., Lagos V.O., Silva S.I., Tabilo E.L., Torrealba M.A. and Jaksic F.M. 1995. Heterogeneous responses of small mammals to an El nino southern oscillation event in North-central Semiarid Chile and the importance of ecological scale. Journal of Mammalogy 76: 580-595.

Molenaar M. 2005. Capacity building got geoinformatics in Africa: an ITC perspective. The International Archives of the Photogrammetry, Remote Sensing, and Spatial Information Sciences 34(6): 1-10.

Mooney H.A. 1977. Convergent Evolution in Chile and California Mediterranean Climate Ecosystems. Dowden, Hutchinson \& Ross, Stroudsburg, Pennsylvania, USA.

Musinguzi M., Bax G. and Tickodri-Togboa S. 2004. Opportunities and challenges for SDI development in developing countries - a case study of Uganda. Proceedings of the $12^{\text {th }}$ International Conference on Geoinformatics-Geospatial Information Research: Bridging the Pacific and Atlantic (June 7-9, 2004), pp. 789-796. University of Gavle, Stockholm, Sweden.

NOAA (National Oceanic and Atmospheric Administration) 2003. What is NDVI? [online] URL: <http://www.csc.noaa.gov/crs/definitions/ NDVI.html>

Petja B.M., Annegarn H.J. and Newby T.S. 2004. A South African approach for using remotely sensed data to influence policy decisions. In: Geoscience 
and Remote Sensing Symposium, IGARSS apos 04 Proceedings (Sept. 20-24, 2004), pp. 556-572. IEEE International, Atlanta, Georgia, USA.

Qiao W. and Xiaofei P. 2004. Study on ecological impact of environmental policy in China's western development - a case study of converting the land for forestry and pasture. In: Proceedings of the $12^{\text {th }}$ International Conference on Geoinformatics - Geospatial Information Research: Bridging the Pacific and Atlanti (June 7-9, 2004), pp. 231-242. University of Gavle, Stockholm, Sweden.
Rida A., Serwan M. and Foster I. 2004. An examination of landuse change due to irrigated agriculture in North-East Jordan using geoinformatics. International Journal of Environmental Studies 61(3): 337-350.

Zaharia A. 2005. Jurisdical protection of waters and aquatic ecosystems in Romania. In: From Pharaohs to Geoinformatics, FIG Working Week 2005 and International Conference on the Global Spatial Data Infrastructure (GSDI-8) (April 16-21, 2005), pp. 432-765. Cairo, Egypt. 